\title{
Asymptomatic Solitary Osteochondroma of Cervical Spine in 17 Year Old Boy
}

Buvaneswari S* and Venkatraman I

Department of Radio Diagnosis, Sree Balaji Medical

College \& Hospital, India

*Corresponding author: Buvaneswari

Shanmuganathan, Department of Radio diagnosis, Sree Balaji Medical College \& Bharath University, Chennai, India

Received: July 17, 2017; Accepted: September 07, 2017; Published: September 18, 2017

\begin{abstract}
Osteochondroma, otherwise known as osteocartilagenous exostoses, is the most common benign tumour of long bones. It can present as solitary or multiple lesions. Cervical osteochondroma is rare accounting for only for approximately 1-4\% of osteochondromas. We report an unusual case of a solitary cervical osteochondroma as an incidental finding in 17 years old boy who underwent Computed Tomography (CT) of Paranasal Sinuses (PNS) in our Department. spine

Keywords: Osteochondroma; Osteocartilagenous exostoses; Cervical
\end{abstract}

\section{Introduction}

Osteochondroma is mostly seen in the long bones and is an ectopic development of cartilage growth plate. The tumor commonly occurs in the proximal humerus, distal femur and metaphysic of tibia. However, the incidence rate of the tumor in the spine is rare, measuring only $\sim 1-4 \%$ [1]. We report here a rare case of incidentally found asymptomatic solitary osteochondroma arising from the right pedicle of $\mathrm{C} 2$ vertebra (Figure $1 \mathrm{~A} \& \mathrm{~B})$.

\section{Case Report}

A 17-year-old boy referred to our Department for CT PNS from ENT department, with complaints of chronic nasal discharge and nasal block for 1 year. He did not have fever, cough, weight loss, neck pain and loss of appetite. A non-contrast CT PNS was done. Incidentally we found a bony out growth measuring $\sim 13 \times 8.7 \mathrm{~mm}$ arising from the right pedicle of $\mathrm{C} 2$ vertebra. Cortical and trabecular continuity were maintained between the lesion and the $\mathrm{C} 2$ pedicle. Plain radiograph of cervical spine antero posterior and lateral view showed a bony lesion with well-defined margins of arising from the right pedicle of $\mathrm{C} 2$ vertebra (Figure 2).

\section{Discussion}

Osteochondroma is an outgrowth of the growth plate and is made up of both bone and cartilage. The incidence of spinal osteochondromas varies, depending upon solitary or multiple forms. Solitary osteochondromas are seen in $2^{\text {nd }}$ and $3^{\text {rd }}$ decades with Male: Female ratio (2.5:1). In literature occurrence of spinal osteochondromas in old age also have been reported [2]. The most common symptoms of osteochondroma is a nontender, painless, cosmetic deformity and slowly enlarging exophytic mass. Complications of osteochondroma include bony deformity, vascular occlusion, fracture, bursa formation, neurologic deficits and malignant transformation [3].

In our case, osteochondroma arising from the right pedicle of the C2 vertebra (Figure $3 \mathrm{~A} \& \mathrm{Bc}$ ). Several reports of $\mathrm{C} 2$ osteochondromadid not present with neurological deficits have been previously reported in the literature [4].

The radiographic appearance of osteochondroma is sessile or pedunculated bonelike projection, with periosteum and cortex that continuous with the host bone.

In spinal osteochondromas $\mathrm{CT}$ is the imaging modality of choice and demonstrates the bony and cartilage components of the tumor and its relationship to the vertebral and neural elements of the spine [5].

CT findings of spinal osteochondromas are smooth bordered, well demarcated mass, bonelike density with scattered calcifications, osteosclerotic changes in adjacent bone, para spinal dumb bell or eccentric intra spinal location and without contrast enhancement.

MRI can be use if suspecting malignant transformation. The cartilage cap $>2 \mathrm{~cm}$ suspects malignancy. Bone scintigraphy can evaluate for the presence of additional osteochondromas.

There is no imaging differential diagnosis for a typical osteochondroma showing bone outgrowth with cortical and trabecular discontinuity.

\section{Conclusion}

Spinal osteochondroma is difficult to diagnose on plain radiographs, unless it is typically appears as a pedunculated bony projection. In our case, plain radiographs showed a smooth ossified lesion (bone-like projection) between $\mathrm{C} 1$ and $\mathrm{C} 2$ vertebrae. CT demonstrate bony density growth arising from the right pedicle of C2 vertebra.

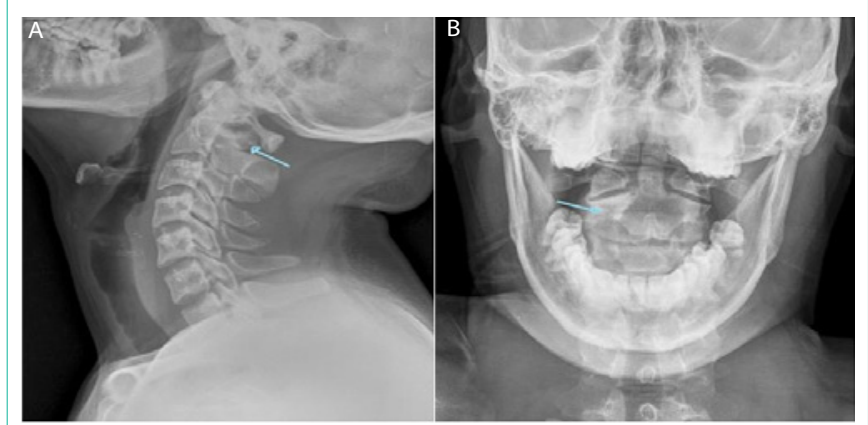

Figure 1A\&B: $X$-ray lateral view shows well marginated bony projection noted between $\mathrm{C} 1$ and $\mathrm{C} 2$ vertebra.
Austin J Radiol - Volume 4 Issue 2 - 2017

ISSN : 2473-0637 | www.austinpublishing group.com

Buvaneswari et al. (C) All rights are reserved
Citation: Buvaneswari S and Venkatraman I. Asymptomatic Solitary Osteochondroma of Cervical Spine in 17 Year Old Boy. Austin J Radiol. 2017; 4(2): 1071. 


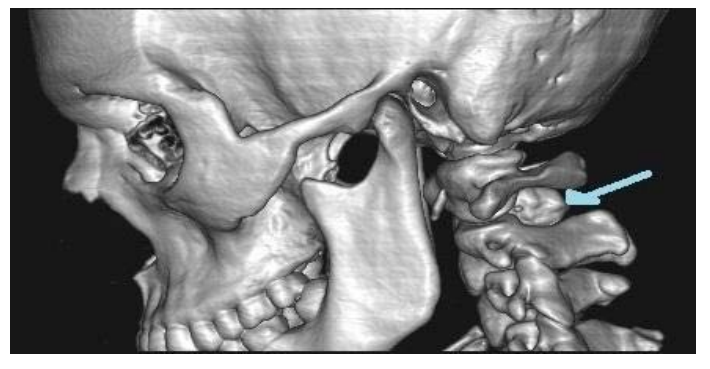

Figure 2: Volume rendering image shows bony like projecting mass noted between $\mathrm{C} 1$ and $\mathrm{C} 2$ vertebra.
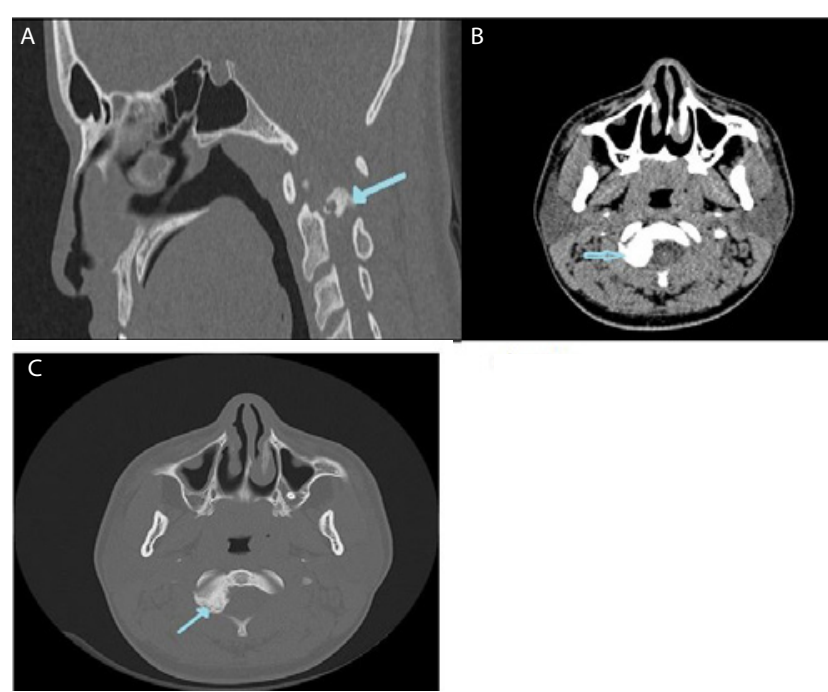

Figure 3: 3A sagittal, 3B \& 3C axial sections of CT shows bony outgrowth arising from right pedicle of $\mathrm{C} 2$ vertebra.
An asymptomatic osteochondromas seen here requires no treatment. If osteochondroma is associated pain or neurologic abnormality, it should be excised at its base. After excision of the cartilage cap, the recurrence does not occur. Laminectomy with decompression of neural elements is the treatment of choice for a symptomatic cervical osteochondroma [6].

\section{References}

1. ToruAsari, Naoki Echigoya, Norihiro Sasaki,Gentaro Kumagi, Kazumasa Ueyama. Cervical myelopathy due to a solitary osteochondroma: a case report. springer plus. 2016; 5: 535

2. Duttaluru, SeshadriSekar, Injeti Babjisyamkumar, Sathish Vandanapu, Bhavanam Hanuma Srinivas, Chandra Srinivas Rao. Solitary lumbarosteochondroma arising from L3 lamina presenting as lump -Rare case report and review of literature. 2015.

3. Ali Nawaz Khan, MBBS, FRCS, FRCP, FRCR Consultant Radiologist and Honorary Professor, North Manchester General Hospital Pennine Acute NHS Trust, UK-Imaging in osteochondroma and osteochondromatosis.

4. Chatzidakis E, Lypiridis S, Kazdaglis G, Chatzikonstadinou K, Papatheodorou G. A rare case of solitary osteochondroma of the dens of the $\mathrm{C} 2$ vertebra. Acta Neurochir. 2007;149: 637-638.

5. Patnaik S, Jyotsnarani Y, Uppin SG, Susarla R. Imaging features of primary tumors of the spine: A pictorial essay. Indian J Radiol Imaging. 2016; 26: 279-289.

6. Victory F, Ali K. Solitary, asymptomatic, posterior, vertebral, intracanal, cervical spine osteochondroma. Radiology Case Reports. 2011; 6: 572.
Austin J Radiol - Volume 4 Issue 2 - 2017

ISSN : 2473-0637 | www.austinpublishing group.com

Buvaneswari et al. (c) All rights are reserved
Citation: Buvaneswari S and Venkatraman I. Asymptomatic Solitary Osteochondroma of Cervical Spine in 17 Year Old Boy. Austin J Radiol. 2017; 4(2): 1071. 